\title{
Sistemas Integrados de Gestão: Proposta para um Procedimento de Decisão Multicritérios para Avaliação Estratégica.
}

\author{
Alberto de Medeiros Júnior \\ alberto.medeiros@poli.usp.br \\ Tamio Shimizu \\ tmshimiz@usp.br
}

\begin{abstract}
Resumo
Os Sistemas Integrados de Gestão, também conhecidos como ERP (Enterprise Resource Planning), vem tendo ampla utilização nas organizações a partir do final do século passado. Por exigir um investimento de elevado valor financeiro para a sua implantação, os responsáveis pela sua aquisição devem tomar cuidados especiais, uma vez que os seus resultados positivos ou negativos somente surgem após longo período de implantação, às vezes após muitos anos. Sendo um problema complexo, repleto de incertezas e riscos, os decisores tomam muito de seu tempo para analisar os diversos critérios e funcionalidades das ofertas de sistemas recebidas. $\mathrm{O}$ artigo propões-se a apresentar um procedimento que possibilite às empresas analisar quando do interesse pela aquisição de um ERP, qual das ofertas disponíveis estará mais adequada às suas necessidades de negócio, baseado em um método multicritérios de apoio à decisão.
\end{abstract}

Palavras-chave: Tecnologia de Informação. Seleção de software. ERP - Enterprise Resource Planning. Sistemas Multicritérios de Suporte à Decisão. ANP - Analytic Network Process, Técnica Delphi.

\begin{abstract}
The use of Integrated Management Systems, also known as ERP (Enterprise Resource Planning), are widely accepted by organizations since beginning of the nineties. As its implementation means a high financial value investment, the responsible team for its acquisition has to take special cares, once their positive or negative results will appear only after long implementation period, often after many years. As it is a complex decision problem, evolving uncertainties and risks, the decision agents spend a lot of time to analyze the several criteria and functionalities from received offers. The paper presents a proposal which makes possible the companies analyzing during ERP acquisition phase, the available offers more adapted to their business requirements, based on a multi-criteria support decision method.
\end{abstract}

Keywords: Information Technology. Software selection. ERP - Enterprise Resource Planning. Multi-criteria Decision Support System. ANP - Analytic Network Process. Delphi Method.

\section{Introdução}

Nos anos 90 as grandes empresas adquiriram amplamente os chamados Sistemas Integrados de Gestão, também, conhecidos como ERP (Enterprise Resource Planning). Trata-se de uma aplicação que permite às empresas automatizar e integrar substancial parcela de seus processos, envolvendo finanças, controles, logística, suprimentos, manufatura, vendas e recursos humanos, possibilitando o compartilhamento de dados e a uniformização de processos de negócios, além de produzir e utilizar informações em tempo real. (COLÂNGELO FILHO, 2001; TURBAN; RAINER; POTTER, 2003; LAUDON; LAUDON, 2004; O'BRIEN, 2004; SLACK; CHAMBERS; JOHNSTON, 2002)

O ERP é considerado por muitos estudiosos como uma evolução do MRP (Material Requirement Planning) e do MRP II (Manufacturing Resource Planning), que são sistemas próprios 
da administração da produção. O primeiro é utilizado para o levantamento de necessidades de materiais e o segundo inclui a avaliação das capacidades de recursos da manufatura e outras funcionalidades (CORREAA; GIANESI; CAON. 1997; SLACK; CHAMBERS; JOHNSTON, 2002; TURBAN; RAINER; POTTER, 2003). Ele possui, porém, mais funcionalidades e interatividade que o MRP e o MRP II, e inclui vários outros aspectos como, por exemplo, contábil, financeiro, comercial, recursos humanos, engenharia etc. (LAURINDO; MESQUITA, 2000) e utiliza técnicas sofisticadas de modelagem e normas comerciais. (TURBAN; RAINER; POTTER, op. cit).

Os Sistemas Integrados de Gestão são constituídos de diversos componentes com a finalidade de abranger todas as áreas das empresas e cada vez mais se juntam novas soluções.

É usual que os produtores de ERP divulguem que os seus sistemas possibilitam a cobertura de todos os recursos de um negócio, porém, é sabido, que na prática, apesar da constante atividade de inovar das empresas produtoras de ERP, isso não corresponde à realidade, provocando uma falta de plena aderência do ERP ao Negócio.

Este é um dos fatores que dificultam a decisão da aquisição de um Sistema Integrado de Gestão, sendo um problema que atinge as empresas em todo o mundo, mas atinge em maior intensidade as de médio e pequeno porte, uma vez que as grandes procuram se prevenir do insucesso com análises prévias mais elaboradas. E mesmo assim elas erram, o que é bem conhecido pela comunidade de Tecnologia de Informação.

Estudo desenvolvido pelo Standish Group (EXTREME CHAOS, 2001), empresa de consultoria e pesquisa de aplicações em missões críticas, aponta que existe uma alta participação da préimplantação e do planejamento de implantação dentre os fatores críticos de sucesso. Isto torna relevante uma análise prévia detalhada, por parte das organizações, para uma definição adequada na aquisição de um ERP.

Considerando-se que, para Colângelo Filho (2001), quanto maior for a aderência, menor será a sua quantidade de lacunas (gaps), existe a necessidade de uma avaliação apropriada para a seleção de sistemas que seja a mais aprofundada possível. As lacunas são cobertas pelas chamadas customizações.

Os fornecedores de sistemas de gestão desenvolveram métodos próprios não somente para a implantação como, também, para diagnóstico da aderência. Os seus resultados, porém, servem para atender aos próprios interesses e não aos

São freqüentes e conhecidos pela comunidade da TI os casos de insucesso na implantação de sistemas de gestão em grandes corporações. Estudo efetuado pelo Standish Group (2004) demonstra que em pesquisa publicada nos Estados Unidos no terceiro trimestre de 2004 (tabela 1.1), na qual $82 \%$ dos projetos de ERP finalizaram-se, ainda que para $53 \%$ a finalização seja questionável (challenged), pois foi realizada com estouro de orçamento e/ou de prazos e/ou implantação com poucos recursos, comparados aos originalmente especificados. Há, 
ainda 19\% de implantações mal sucedidas (failed) cujos projetos foram cancelados antes de serem completados ou nunca foram implantados.

Conseqüentemente, observa-se que apenas $29 \%$ do total foram efetivamente bem sucedidos (succeeded), ou seja, completados no devido tempo planejado e dentro do valor orçado, com os requisitos especificados originalmente.

Tabela 1.1

Finalização de projetos de implantação de ERP entre 1994 e 2004 (terceiro trimestre) - em \%

\begin{tabular}{lrrrrr}
\hline & 1994 & 1996 & 1998 & 2000 & 2004 \\
\hline Bem sucedido & 16 & 27 & 26 & 28 & 29 \\
Mal sucedido & 31 & 40 & 28 & 23 & 18 \\
Questionável & 53 & 33 & 46 & 49 & 53 \\
\hline \multicolumn{4}{l}{ Fonte: Adaptado de Extreme Chaos $(2001,2004)$}
\end{tabular}

A redução de finalizações mal sucedidas, entre outras, é decorrente de soluções melhor desenvolvidas e mais amigáveis na parametrização, melhor treinamento dos consultores, maior consciência das empresas quanto aos fatores críticos de sucesso (FCS) na implantação dos sistemas.

Por outro lado, a elevação de quantidade de projetos questionáveis, possibilita a dedução que existem, ainda, inúmeras lacunas a serem preenchidas, evidenciando a necessidade de melhor gestão tanto do planejamento de implantação e quanto da seleção no momento da aquisição do sistema.

Entende-se que uma das causas de insucesso da implantação dos Sistemas Integrados de Gestão é decorrente de uma seleção mal conduzida. Por isto, entendeu-se haver a necessidade de desenvolver-se um procedimento de avaliação para seleção de sistema que esteja alinhado ao negócio possibilitando assim ao decisor, um recurso que reduza os riscos e incertezas da decisão.

Para a pesquisa relatada neste artigo foi utilizado o sistema de informação de suporte à decisão muilticritérios ANP (Analytical Network Process) como instrumento de pesquisa, cujos critérios de avaliação foram classificados por um painel de especialistas em ERP.

\section{Referencial teórico}

\section{1 Razões para adoção de Sistema Integrado de Gestão}

A opção em se utilizar um ERP, apesar de ser um desejo dos altos executivos de todas as empresas, sempre é uma decisão complexa. É usual uma expectativa acima do que as aplicações geralmente oferecem.

Colângelo Filho (2001) considera que há três classes de motivos que levam uma empresa a implantar um ERP: 
- Negócios: que estão associados à melhoria da lucratividade ou do fortalecimento da posição competitiva da organização.

- Legislação: que estão ligados às exigências legais as quais a empresa deve cumprir e que não são atendidos pelos sistemas legados (aqueles em uso na empresa).

- Tecnologia: que são relacionados às mudanças necessárias decorrentes da obsolescência econômica das tecnologias em uso ou a exigências de parceiros de negócios.

Há, no entanto, algumas expectativas mínimas comuns (KOCH, 1999; COLÂNGELO FILHO, 2001), destacando-se:

- Informações gerenciais ou executivas.

- Informações financeiras integradas.

- Informações integradas de pedidos de clientes.

- Padronização e agilização de processos de manufatura.

- Redução de inventário.

- Informações padronizadas de recursos humanos.

- Interesse em diferenciar-se da concorrência..

- Busca por maior competitividade global.

- Preparação para o crescimento.

- Flexibilidade.

- Falta de integração entre os sistemas legados.

- Elevado número de fornecedores de sistemas.

- Obsolescência de equipamentos ou sistemas de informação.

- Exigências tecnológicas de parceiros de negócios.

Para Buonanno et al. (2005) há seis fatores que devem ser considerados na adoção de um ERP:

1. Tamanho da empresa.

2. Área de mercado.

3. Participação como membro de um grupo empresarial.

4. Presença de filiais.

5. Nível de diversificação de produtos, mercados e tecnologias.

6. Grau de extensões funcionais. 


\subsection{Razões para adoção parcial ou não adoção de ERP}

Os administradores das empresas, de uma forma geral, sonham em possuir um sistema integrado que Ihes possibilite o controle total da empresa, mas isto nem sempre é totalmente possível.

Uma das razões é a falta de funcionalidades específicas. Enquanto a maior parte dos módulos administrativos dos sistemas corporativos geralmente atende às empresas adequadamente, nem sempre o módulo de manufatura atende plenamente os seus anseios, uma vez que muitos sistemas ERP têm esse módulo voltado à produção discreta, que não suportam alguns processos industriais, como a produção de têxteis, alimentos e papéis, por exemplo. (MARKUS; TANIS, 2000)

Como é usual que a customização do módulo de manufatura para atender as necessidades da produção seja custosa e demorada, a solução recorrente é a empresa adquirir módulos específicos para isto, desenvolvidos por empresas especializadas, ou mesmo desenvolvendo-os internamente e conectando-os, por interfaces, a partes dos módulos administrativos do sistema corporativo.

Empresas que modificam suas estruturas organizacionais e negócios com freqüência, TAMbém, têm dificuldades em obter sistemas que as atendam com a devida flexibilidade exigida.

Outro fator considerado é a disponibilidade de opções para elevar o nível de integração de sistemas. Data warehouse e CRM (Customer Relationship Management), por exemplo, utilizam dados alimentados por sistemas transacionais, como o de um ERP. Se esses dados forem pobres, então o data warehouse e o CRM terão pouco a oferecer de resultados.

\subsection{Seleção de ERP}

A seleção de um ERP é sempre uma das mais complexas e arriscadas decisões tomadas pelas empresas.

O processo de seleção (etapa cinco do roteiro ideal) usualmente inicia-se pela emissão de uma requisição de proposta conhecida por RFP sigla de Request for Proposal, que é um convite aos fornecedores para que eles submetam à organização as ofertas para produtos ou serviços específicos.

Há, ainda outras duas modalidades de requisição a fornecedores: o RFQ (Request for Quotation) que é apenas uma solicitação do preço do produto, quando os detalhes de aderência já são conhecidos e o RFI (Request for Information) que é uma requisição aos fornecedores para que informem qual ou quais de seus produtos podem atender a uma necessidade específica.

Um RFP, no entanto, envolve não apenas o preço, mas deve incluir, ainda, informações mais profundas sobre a fornecedora de produto ou serviço, tais como: dados financeiros, compe- 
tência técnica, previsão de implantação, referências comerciais e principalmente um detalhamento sobre o produto a fim de se verificar o seu grau de aderência aos negócios da empresa compradora.

Isso é feito pelas respostas dadas por potenciais fornecedores de ERP a um questionário preparado com os requisitos da organização. Esses requisitos variam de empresa a empresa e, não raro, chegam a centenas de itens a serem analisados.

O quadro 2.1 apresenta uma comparação desses critérios dentre os autores mais citados na literatura internacional e um autor nacional.

\begin{tabular}{|c|c|c|c|c|c|c|}
\hline & 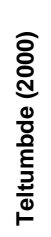 & 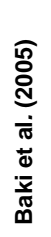 & 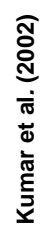 & 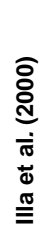 & 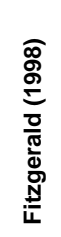 & 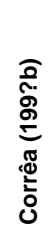 \\
\hline 1. Critérios técnicos & $\mathrm{X}$ & $\mathrm{X}$ & $\mathrm{X}$ & $\mathrm{X}$ & & \\
\hline 2. Funcionalidade & $x$ & $x$ & $\mathrm{x}$ & $\mathrm{x}$ & & \\
\hline 3. Referências do fornecedor & $\mathrm{x}$ & $\mathrm{x}$ & $\mathrm{x}$ & & & $\mathrm{x}$ \\
\hline 4. "Implantabilidade" & $\mathrm{x}$ & $\mathrm{x}$ & & & $\mathrm{x}$ & \\
\hline 5. Ajuste estratégico & $\mathrm{x}$ & & & & $\mathrm{x}$ & \\
\hline 6. Riscos & $\mathrm{x}$ & & & & $\mathrm{x}$ & \\
\hline 7. Flexibilidade & $\mathrm{x}$ & & & & $\mathrm{x}$ & \\
\hline 8. Custo & $\mathrm{x}$ & $\mathrm{x}$ & & & $\mathrm{x}$ & $\mathrm{x}$ \\
\hline 9. Análise de benefícios & $\mathrm{x}$ & & & & $\mathrm{x}$ & \\
\hline 10. Serviço e suporte & & $\mathrm{x}$ & $\mathrm{x}$ & & & \\
\hline 11. Confiabilidade do sistema & & $\mathrm{x}$ & $\mathrm{x}$ & & & \\
\hline 12. Facilidade de customização & & $\mathrm{x}$ & $\mathrm{x}$ & & & $\mathrm{x}$ \\
\hline 13. Melhor ajuste com a estrutura organizacional & & $\mathrm{x}$ & $\mathrm{x}$ & & & \\
\hline 14. Ajuste com sistema de matriz e/ou parceiro & & $x$ & $\mathrm{x}$ & & & \\
\hline 15. Integração modular cruzada & & $\mathrm{x}$ & $\mathrm{x}$ & & & $\mathrm{x}$ \\
\hline 16. Consultorias de seleção e implantação & & $\mathrm{x}$ & & $\mathrm{x}$ & & $x$ \\
\hline 17. Método de implantação do software & & $\mathrm{x}$ & & & & $x$ \\
\hline 18. Domínio de conhecimento do fornecedor & & $\mathrm{x}$ & & & & $x$ \\
\hline 19. Posição do fornecedor no mercado & & $\mathrm{x}$ & & & & $\mathrm{x}$ \\
\hline 20. Compatibilidade com outros sistemas & & $\mathrm{x}$ & & & & $x$ \\
\hline 21. Visão do fornecedor & & $\mathrm{x}$ & & & & \\
\hline 22. Mudanças administrativas & $\mathrm{x}$ & & & & & \\
\hline 23. Tempo de implantação & & $\mathrm{x}$ & & & & \\
\hline 24. Escalabilidade para permitir crescimento & & & & & & $x$ \\
\hline 25. Atualização da tecnologia & & & & & & $x$ \\
\hline 26. Facilidade de uso & & & & & & $\mathrm{x}$ \\
\hline 27. Segurança & & & & & & $x$ \\
\hline 28. Localização & & & & & & $\mathrm{x}$ \\
\hline
\end{tabular}


O quadro 2.2 descreve cada um desses critérios:

\begin{tabular}{ll}
\hline Critério & Descrição \\
\hline 1. Critérios técnicos: & O ERP deve estar atualizado nas tendências de TI, particularmente quanto aos sistemas gerenciado- \\
& res de banco de dados, ambiente cliente-servidor, hardware, sistema operacional, etc..
\end{tabular}

2. Funcionalidade:

3. Referências do fornecedor:

4. "Implantabilidade":

5. Ajuste estratégico:

6. Riscos:

7. Flexibilidade:

8. Custo:

9. Análise de benefícios:

10. Serviço e suporte:

11. Confiabilidade do sistema:

12. Facilidade de customização:

13. Melhor ajuste com a estrutura organizacional:

14. Ajuste com sistema de matriz elou parceiro:

15. Integração modular cruzada:

16. Consultorias de seleção e implantação:

17. Método de implantação do software:

18. Domínio de conhecimento do fornecedor:

19. Posição do fornecedor no mercado:

20. Compatibilidade com outros sistemas:

21. Visão do fornecedor:
Tem três aspectos principais: quais áreas funcionais o produto pode cobrir, o quanto o produto é flexível quanto à adaptabilidade e abertura e características específicas de alguns ERPs.

As referências de vendas, a reputação, e a internacionalidade do vendedor, com histórico de projetos bem sucedidos devem ser considerados i para o processo de seleção (BAKI; ÇAKAR, 2005), uma vez que, pela esperada longevidade do sistema, a empresa produtora deve estar preparada para suportálo por esse período (FITZGERALD, 1998).

Muitos projetos são avaliados apenas pelo seu potencial de custos e benefícios, todavia muitas vezes é ignorado o fato que alguns projetos são mais difíceis de serem implantados que outros. Alguns, talvez, nunca consigam efetivamente ir adiante (FITZGERALD, op. cit.).

Um projeto ERP deve refletir a estratégia da empresa nas rápidas trocas de ambientes tecnológico e de negócios graças a um mercado competitivo. Em muitos casos o próprio projeto é resultado direto da estratégia de negócio.

Risco é a medida do grau de possível variação do resultado ou benefícios do projeto. Se essa variação for grande, então o risco é alto (FITZGERALD, op. cit.). Ele está relacionado ao tamanho do investimento e à complexidade da empresa.

É a habilidade do sistema em suportar as necessidades do negócio durante o seu tempo de vida. A falta de flexibilidade irá subutilizar o sistema ou mesmo torná-lo obsoleto (TELTUMBDE, 2000).

O preço de um ERP geralmente é muito alto. O custo total de propriedade (TCO - Total Cost Ownership) do sistema deve incluir, além do preço das licenças, a sua manutenção e atualizações, os demais software exigidos, hardware, inclusive a rede, a consultoria, o treinamento, a equipe de implantação e ainda outros custos. (MABERT; SONI; VENKATARAMANAN, 2000).

Enquanto que, para os negócios os benefícios podem ser muitas vezes fáceis de serem quantificáveis, em um ERP muitos dos mais importantes benefícios não o são, os exemplos são: a redução de tempo de resposta de uma produção, ou o ciclo de desenvolvimento de um produto ou, ainda, a melhor disponibilidade do controle de informação.

Uma instalação completa de ERP pode alcançar um investimento muitas vezes superior ao custo de um software. Por isto, o serviço e o suporte associados tornam-se fatores vitais para o sucesso do negócio entre o usuário e o fornecedor de um sistema.

O sistema deve incorporar as melhores práticas de negócio de cada área, bem como as mais recentes tendências de TI. Essa confiabilidade deve ser verificada com os usuários.

A maioria das empresas necessita customização do ERP, uma vez que existe a necessidade de se adequar uma solução genérica às necessidades específicas da empresa.

A seleção pode ser feita considerando-se a necessidade, ou não, de se contratar mão-de-obra especializada para a implantação utilizando a estrutura organizacional existente na empresa. (BAKI; ÇAKAR, op. cit.)

A compatibilidade com a matriz ou parceiros pode afetar no processo de decisão de algumas empresas. Esta compatibilidade pode, também, afetar o sucesso do projeto. (Ibidem)

O real benefício de um sistema ERP é a integração, a qual deve ser completa entre os módulos. Se ela não existir, além de elevar o custo de implantação (por se elevar o tempo de trabalho), pode afetar a eficiência do sistema que pode decrescer.

Os consultores devem ter experiência nas especificidades da empresa, com conhecimento abrangente dos módulos e devem ser capazes de determinar quais são os recursos do sistema que melhor atenderão a empresa (SOMERS; NELSON, 2001).

O processo de implantação depende visceralmente de uma boa, robusta e testada metodologia (CORRÊA, 199?b) e provocam enormes mudanças nas empresas e, por isso, eles devem ter um método claro.

O desenvolvedor do sistema deve ter conhecimento do ramo de negócio. Se for uma manufatura, a empresa precisa encontrar um software de um fornecedor especializado em sua área de atuação (RAO, 2000).

Os sistemas aprendem com as experiências do passado, por isto, quanto maior for a quantidade de implantações um fornecedor tiver no mercado, maior será a quantidade de melhores práticas (best practices) globais embutidas no ERP.

Nenhuma aplicação pode fazer tudo que uma empresa necessita. Não existe aderência absoluta. A solução selecionada deve ter recursos para integração com os sistemas legados da empresa e com outros software especializados que ela utiliza para cobrir todas as suas necessidades.

Trata-se da visão que o fornecedor tem para o seu produto, ou seja, as modificações planejadas para os seus produtos e serviços para os três a cinco anos a seguir. (HECHT, 1997) 


\begin{tabular}{|c|c|}
\hline Critério & Descrição \\
\hline $\begin{array}{l}\text { 22. Mudanças administra- } \\
\text { tivas: }\end{array}$ & $\begin{array}{l}\text { Implantar ERP é predominantemente um projeto de mudanças administrativas. Os produtores de ERP } \\
\text { procuram impor a sua maneira de fazer negócio (apresentado como "melhores práticas"). Por isto as } \\
\text { empresas precisam adaptar-se a esse modelo. (TELTUMBDE, 2000) }\end{array}$ \\
\hline $\begin{array}{l}\text { 23. Tempo de implanta- } \\
\text { ção: }\end{array}$ & $\begin{array}{l}\text { A implantação de um ERP é altamente custosa e complexa em projetos de grande porte. Para Mabert, } \\
\text { Soni e Venkataramanan (2000) o tempo de implantação está fortemente correlacionado à estratégia de } \\
\text { implantação, podendo, também, ocorrer por mudaças no escopo. Soluções específicas podem tam- } \\
\text { bém reduzir o tempo de implantação (BINGI; SHARMA; GODLA, 1999). }\end{array}$ \\
\hline $\begin{array}{l}\text { 24. Escalabilidade para } \\
\text { permitir crescimento: }\end{array}$ & $\begin{array}{l}\text { A escalabilidade permite o ERP crescer gradualmente, na medida do crescimento dos usuários na } \\
\text { empresa, permitindo o aumento da capacidade das plataformas de hardware e software, evitando } \\
\text { descontinuidades bruscas de trocas completas de plataforma. (CORRÊA, 199?b) }\end{array}$ \\
\hline $\begin{array}{l}\text { 25. Atualização da tecno- } \\
\text { logia: }\end{array}$ & $\begin{array}{l}\text { Uma solução de ERP deve incorporar as novidades tecnológicas que Ihe são relevantes como, por } \\
\text { exemplo, a Internet, intranets, apoio ao EDI com fornecedores e clientes, interfaces gráficas, intercam- } \\
\text { bialidade de dados com planilhas eletrônicas, códigos de barras, correio eletrônico interno, etc. (Ibi- } \\
\text { dem) }\end{array}$ \\
\hline 26. Facilidade de uso: & $\begin{array}{l}\text { Um sistema fácil de ser utilizado é, também um sistema mais fácil de se treinar e de manter os seus } \\
\text { usuários atualizados e ainda facilita o trabalho para convencê-los a comprometer-se com seu uso } \\
\text { obtendo-se, assim, uma utilização adequada. (Ibidem) }\end{array}$ \\
\hline 27. Segurança: & $\begin{array}{l}\text { Os aspectos relacionados à segurança e à integridade dos dados devem ser considerados quando da } \\
\text { aquisição de um sistema. (Ibidem) }\end{array}$ \\
\hline 28. Localização: & $\begin{array}{l}\text { Este é um critério que tem grande importância para empresas que as quais pretendem utilizar siste- } \\
\text { mas desenvolvidos em outros países. }\end{array}$ \\
\hline
\end{tabular}

Quadro 2.2

Critério de avaliação de ERP recolhidos da literatura.

\subsection{Os sistemas de informação para obtenção de vantagem competitiva}

Um dos importantes exercidos pelos sistemas de informação é o suporte às vantagens competitivas. Apresentam-se aqui dois modelos que possibilitam a análise do alinhamento estratégico de uma empresa:

- modelo do impacto estratégico de TI, conforme Nolan e McFarlan (2005) e,

- modelo do alinhamento da estratégica de $\mathrm{TI}$ com a estratégia corporativa, conforme Henderson e Venkatraman (1993).

No modelo do impacto estratégico de $\mathrm{TI}$ desenvolvido por Nolan e McFarlan (2005) considera-se que em algumas organizações as atividades de $\mathrm{TI}$ representam grande importância estratégica, enquanto que, para outras, representa um custo efetivo. Isso reflete na quantidade de tempo que o principal executivo da empresa deve despender pensando em estratégia.

Para identificar os ambientes de TI eles ela-

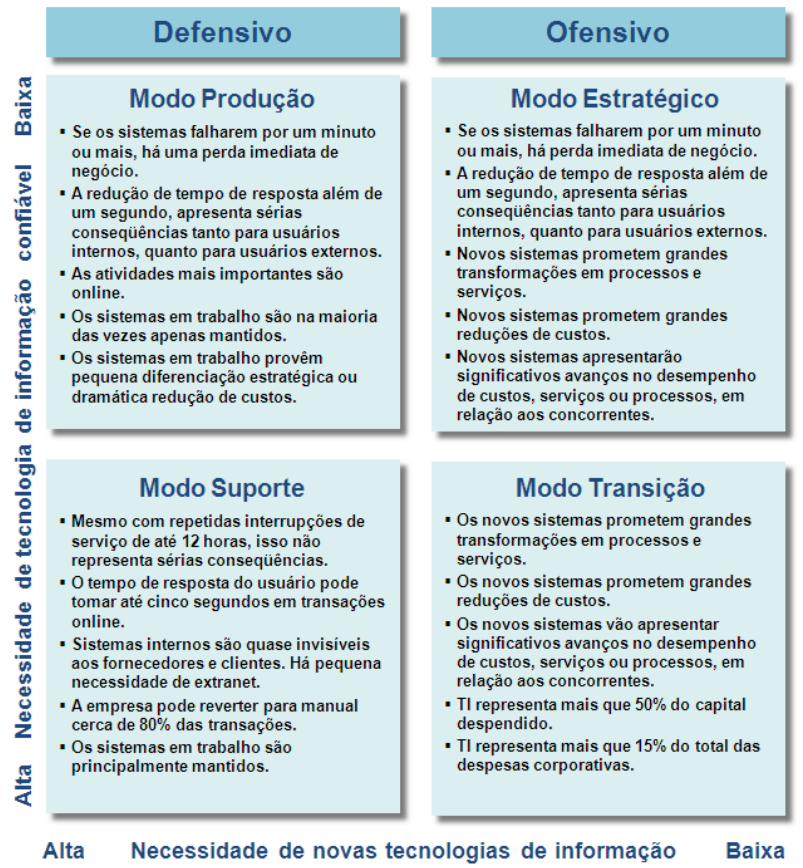

\section{Figura 2.1}

Modelo de impacto estratégico de TI.

Fonte: Nolan e McFarlan (op. cit.) boraram um grid (figura 2.1) que estabelece o enquadramento estratégico das empresas. 
Os quadrantes "produção" e "suporte" formam o grupo dos modos defensivos, onde manter os sistemas funcionando é mais importante na configuração atual da empresa do que competir usando tecnologias emergentes. Neste grupo a diretoria da empresa precisa estar segura que os sistemas tecnológicos estão totalmente protegidos contra potenciais desastres de computador, como bugs, interrupções de energia elétrica, hackers, etc. Os custos devem manter-se sob controle.

Os quadrantes "estratégico" e "transição" formam o grupo dos modos ofensivos onde a visão estratégica de TI está acima ou no mesmo nível da segurança. Os projetos tendem a ser ambiciosos e arriscados uma vez que envolvem substanciais mudanças organizacionais.

O modelo do alinhamento estratégico de TI desenvolvido por Henderson e Venkatraman (1993) possibilita a análise do alinhamento da estratégica de TI com a estratégia corporativa,

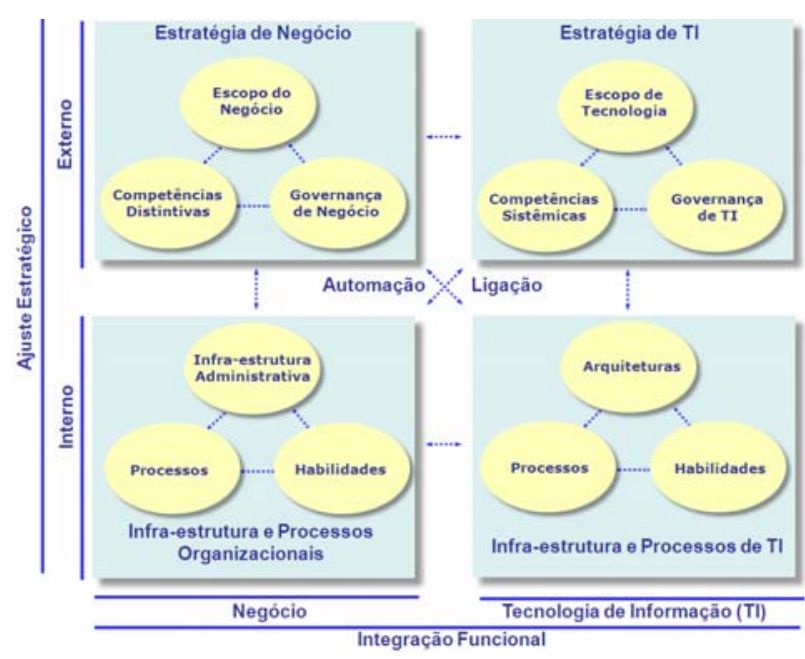

Figura 2.2

Modelo de alinhamento estratégico com conjuntos de escolha.

Fonte: Henderson e Venkatraman (op. cit.) e apresenta quatro blocos que representam os quatro domínios da escolha estratégica (figura 2.2).

O par de blocos à esquerda foca o Negócio, enquanto o par da direita foca a Tecnologia de Informação. Por outro ponto de vista, o par superior representa a Estratégia (e o domínio externo), enquanto o par inferior representa a Infra-estrutura (e o domínio interno).

O inter-relacionamento é tal que qualquer decisão estratégica envolve decisões em um ou mais domínios. Um domínio orienta ou impacta atividades em um ou mais dos outros. A estratégia de negócio, por exemplo, impacta a infra-estrutura organizacional e a estratégia de TI impacta a infra-estrutura de TI. Cada bloco possui três conjuntos de escolha (quadro 2.3): 


\section{Estratégia de Negócios \\ Escopo do negócio: \\ São as decisões e escolhas que definem o campo de concor- rência da empresa como: produtos, nicho, clientes, etc. Inclui as forças competitivas de Porter (1989). \\ As perguntas típicas são: qual é o nosso negócio? Quais são os nossos produtos, serviços e mercados-alvos?}

\section{Competências distintivas:}

São as áreas que determinam como as empresas vão competir na entrega de seus produtos ou serviços. Essas decisões determinam os atributos da estratégia, tais como política de preços, foco na qualidade etc., que criam a aptidão da empresa em diferenciar seus produtos ou serviços da concorrência. Definem por que um cliente escolhe comprar ou usar o que uma empresa em particular oferece.

A pergunta típica é: no que devemos nos concentrar em fazer melhor a fim de nos distinguirmos de nossos concorrentes?

\section{Governança do negócio:}

São as decisões referentes a eventuais parcerias ou a terceirizações visando obter vantagens de escala para o atendimento de um mercado em particular. Define se uma empresas vai entrar em um mercado em particular isoladamente ou em aliança, parceria ou terceirização com outras empresas.

A pergunta típica é: de que relações com negócios externos e/ou joint ventures nós dependemos?

\section{Estratégia de TI \\ Escopo de tecnologia:}

Especifica as tecnologias críticas responsáveis pelo sucesso da organização, tais como sistemas de base de conhecimento, robotização, multimeios, etc.

A pergunta típica é: que tecnologias tanto suportam quanto criam oportunidades de negócios estratégicos?

\section{Competências sistêmicas:}

Características importantes de TI críticas na criação ou extensão das estratégias de negócios, tais como conectividade, acessibilidade, confiabilidade etc.

A pergunta típica é: que características de TI criam vantagens de negócios?

\section{Governança de TI:}

Definição da propriedade da tecnologia (usuário final, comitê gestor, etc.) ou da possibilidade de alianças tecnológicas como parcerias, terceirizações ou ambas, ou, ainda, decisões comprar ou fazer (make-or-buy).

A pergunta típica é: de quais relacionamentos externos como terceirização, decisões comprar ou fazer etc., nós dependemos?

\section{Infra-estrutura e Processos Organizacionais \\ Infra-estrutura administrativa:}

São escolhas que estabelecem a estrutura de gestão e de processo de trabalho que uma empresa vai operar. É a estrutura de regras,responsabilidades e poder da empresa.

As perguntas típicas são: qual é a nossa estrutura organizacional? Quem se reporta a quem?

\section{Processos:}

São escolhas que determinam como as funções básicas do negócio irão operar ou fluir. Definem o quanto os fluxos de trabalho serão reestruturados ou integrados para melhorar a eficiência e a eficácia das empresas.

Neste campo, pode-se avaliar a relação entre os processos e a $\mathrm{TI}$, uma vez que melhorias de processos podem representar modificações em TI ou o uso efetivo de TI pode representar a necessidade de uma reestruturação nos processos administrativos.

A pergunta típica é: quais são os nossos processos chave de negócio?

\section{Habilidades:}

São escolhas onde se devem definir claramente os recursos humanos envolvidos na estratégia e a eventual necessidade de contratação de serviços terceirizados. Devem ser considerados a experiência, os valores e as normas que se exigem dos profissionais para que a estratégia tenha sucesso. Devem observar, ainda, se essas habilidades vão implicar em conflito com as normas e os valores tradicionais das empresas.

A pergunta típica é: que recursos humanos nós temos (ou necessitamos) para acompanhar nossas concorrências específicas?

\section{Infra-estrutura e Processos de TI}

\section{Arquiteturas:}

São as escolhas, prioridades ou políticas que sintetizam as aplicações, dados, software e hardware em uma plataforma coesa.

A pergunta típica é: quais são as nossas opções de plataformas, hardware, software, configurações de rede e arquitetura de dados?

\section{Processos:}

É a configuração quanto às práticas de desenvolvimento de aplicações e controles gerenciais dos sistemas.

A pergunta típica é: quais são os processos de TI: desenvolvimento, manutenção, operações de sistema, administração de base de dados?

\section{Habilidades:}

São as experiências, competências, comprometimentos, valores e normas que regem as tarefas no objetivo da produção e entrega de produtos e/ou serviços de TI.

A pergunta típica é: quais são as habilidades que os nossos gestores de $\mathrm{TI}$, e pessoal de apoio, necessitam para manter a arquitetura e executar os processos?

Quadro 2.3 - Conjuntos de escolha no modelo de alinhamento estratégico

Fontes: Luftman; Lewis; Oldach, 1993; Curtin, 1996

\section{Metodologia de pesquisa}


A pesquisa visou responder às seguintes perguntas:

1. Como formular um procedimento para decisão na seleção de Sistema Integrado de Gestão que possibilite inter-relacionar critérios de avaliação para que a estratégia de Tecnologia de Informação esteja alinhada à estratégia de Negócio?

2. Como classificar os critérios relevantes a serem avaliados nos procedimentos de seleção de um Sistema Integrado de Gestão para avaliá-lo adequadamente?

As repostas foram obtidas pela combinação de dois métodos de pesquisa. Para resposta à primeira oi utilizado o Estudo de Caso múltiplo, utilizando o ANP (Analytic Network Process) desenvolvido por Saaty $(2001,2005)$ e para a resposta à segunda, que foi realizada a Técnica Delphi

A aplicação da Técnica Delphi classificou os critérios de avaliação utilizados no Estudo de Caso.

\subsection{Estudo de Caso}

O Estudo de Caso partiu das seguintes proposições:

1. Existem critérios que são comuns a diversas organizações.

2. Alguns critérios somente são interessantes a algumas organizações.

3. O ANP é adequado como ferramenta para análise para seleção de ERP;

4. O uso do ANP construído como o modelo de alinhamento estratégico (modelo de Henderson e Venkatraman) possibilita que a avaliação considere as importâncias de Negócio e de TI atribuídas à avaliação.

O objetivo do Estudo de Caso foi validar o modelo criado no instrumento de pesquisa nele utilizado.

O ANP possibilita o julgamento multicritérios de avaliação de ERP agrupados por áreas de dependência comparando-se tanto os critérios e quanto os agrupamentos par-a-par. Com isso pode-se estabelecer a importância de cada critério quanto ao outro em um agrupamento e também a importância de um agrupamento face a outro.

O resultado foi a classificação das alternativas as quais, no Estudo de Caso, são os diversos ERPs que estão sob análise.

Para se avaliar a terceira e quarta proposições (figura 3.1), foi construído tomando-se como agrupamentos os domínios e escolhas (quadro 3.1) conforme o modelo de Henderson e Venkatraman (1993), o qual foi aplicado no software SuperDecisions destinado a avaliar o ANP em quatro empresas, sendo duas de grande, uma de médio e uma de pequeno porte. 
Em todos os casos as empresas já tinham passado por seleção de ERP e os entrevistados participaram ativamente desse processo.

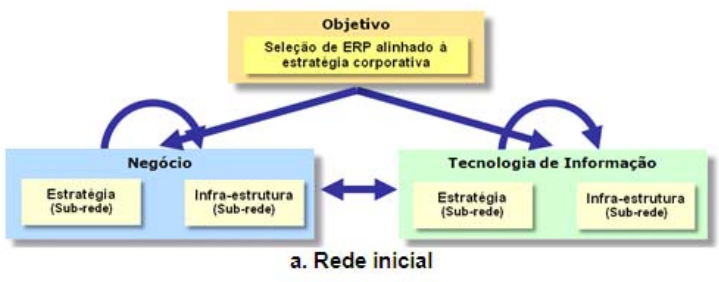

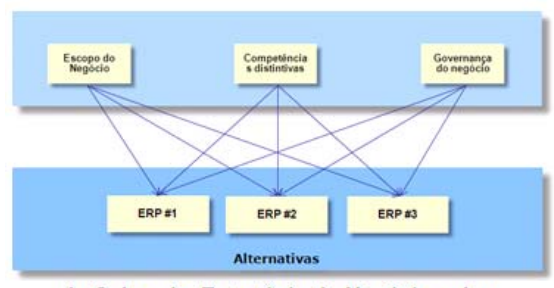

b. Sub-rede: Estratégia de Negócio sob o agrupamento Negócio

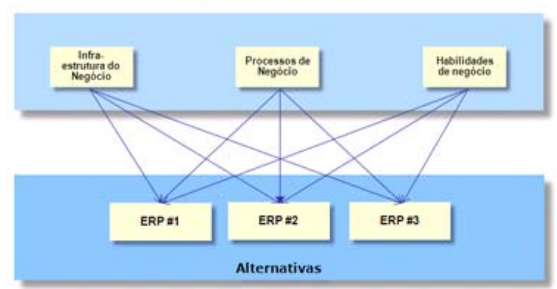

d. Sub-rede: Infra-estrutura de Negócio sob o

Figura 3.1

Representação gráfica da rede e sub-redes na escolha de ERP alinhado à estratégia corporativa utilizadas como instrumento de pesquisa nos Estudos de Caso.

\begin{tabular}{|c|c|c|}
\hline Sub-rede & Escolha & Critério \\
\hline \multirow{3}{*}{ Estratégia de TI } & Escopo de TI & $\begin{array}{l}\text { Flexibilidade } \\
\text { Funcionalidade }\end{array}$ \\
\hline & $\begin{array}{l}\text { Competências } \\
\text { sistêmicas }\end{array}$ & $\begin{array}{l}\text { Confiabilidade do sistema } \\
\text { Custo } \\
\text { Facilidade de customização } \\
\text { Implantabilidade } \\
\text { Referências do fornecedor } \\
\text { Segurança } \\
\text { Tempo de implantação }\end{array}$ \\
\hline & Governança de TI & $\begin{array}{l}\text { Ajuste com sistema de matriz e/ou parceiros } \\
\text { Compatibilidade com outros sistemas }\end{array}$ \\
\hline \multirow{3}{*}{ Infra-estrutura de TI } & Arquiteturas de $\mathrm{TI}$ & $\begin{array}{l}\text { Critérios técnicos } \\
\text { Escalabilidade para permitir crescimento }\end{array}$ \\
\hline & Processos de $\mathrm{TI}$ & $\begin{array}{l}\text { Configuração adequada do software } \\
\text { Integração modular cruzada }\end{array}$ \\
\hline & Habilidades de TI & $\begin{array}{l}\text { Consultorias de seleção e implantação } \\
\text { Domínio de conhecimento do fornecedor } \\
\text { Serviço e suporte }\end{array}$ \\
\hline
\end{tabular}

\section{Quadro 3.1}

Critérios para avaliação de ERP atribuídos às escolhas no modelo de alinhamento estratégico nas subredes subordinadas à Tecnologia de Informação. 


\subsection{Técnica Delphi}

Para se estabelecer quais seriam os critérios relevantes a serem utilizados no instrumento de pesquisa do Estudo de Caso, foi feito um levantamento na literatura científica existente e foram considerados 32 critérios para avaliação de ERP, dos quais 28 estão apresentados no quadro 2.2 e os demais foram obtidos dos Fatores Críticos de Sucesso, conforme apresentados no quadro 3.2 :

\begin{tabular}{|c|c|}
\hline Critério & Descrição \\
\hline Evitar customizações & $\begin{array}{l}\text { Sempre que e até quanto possível, a organização onde está sendo implantado o ERP, deve } \\
\text { tentar adotar os processos e opções nele contidos ao invés de modificá-lo para ajustá-lo a } \\
\text { uma prática particular de negócio. Por isso recomenda-se que a customização adira às } \\
\text { especificações padrões que o software suporta. (ESTEVES-SOUSA; PASTOR-COLLADO, } \\
2000 \text { ) }\end{array}$ \\
\hline Versão adequada do sistema & $\begin{array}{l}\text { Uma organização necessita determinar qual versão irá ser implantada. Atualizações freqüen- } \\
\text { tes podem causar problemas. Isto é particularmente relevante quando a organização deve } \\
\text { esperar por uma atualização (release) futura que inclua a funcionalidade exigida. (Ibidem) }\end{array}$ \\
\hline Conhecimento dos sistemas legados & $\begin{array}{l}\text { A configuração envolve a adaptação das funcionalidades genéricas de um pacote às neces- } \\
\text { sidades particulares de uma organização. Há, também, a necessidade de configurar as } \\
\text { interfaces conforme as necessidades dos usuários. (Ibidem) }\end{array}$ \\
\hline Conhecimento dos sistemas legados & $\begin{array}{l}\text { Os sistemas legados são os sistemas de TI e de negócios utilizados antes da implantação } \\
\text { do ERP que encapsulam os processos de negócio existentes; a estrutura da organização; a } \\
\text { cultura e a tecnologia de informação. Eles são boas fontes de informações para as implanta- } \\
\text { ções de ERP e os possíveis problemas que podem ser encontrados durante a implantação. } \\
\text { (lbidem) }\end{array}$ \\
\hline
\end{tabular}

Quadro 3.2

Fatores Críticos de Sucesso analisados como critérios de seleção de ERP

Esses critérios foram classificados por um painel de 27 especialistas em ERP, quanto à sua importância e quanto à necessidade ou possibilidade de serem utilizados no instrumento de pesquisa, tendo-se a Técnica Delphi como metodologia de pesquisa.

Após essa classificação, 17 desses critérios foram considerados como sendo os mais relvantes e são esses que foram utilizados no instrumento de pesquisa do Estudo de Caso (quadro 3.1).

\section{Considerações finais}

A combinação de dois métodos de pesquisa possibilitou a elaboração do PASS - Procedimento de Avaliação para Seleção de Sistemas Integrados de Gestão (PASS) o que propicia às empresas uma ferramenta para avaliação adequada de Sistemas Integrados de Gestão.

O seu núcleo é a utilização do ANP com os agrupamentos construídos conforme o alinhamento estratégico segundo Herderson e Venkatraman (1993).

Por ser possível estabelecer-se uma quantidade muito elevada de critérios de avaliação, além mesmo daquela que foi utilizada nesta tese, há a necessidade de utilizarem-se aqueles que representem efetivamente o atendimento aos requisitos das empresas. 
A Técnica Delphi mostrou-se adequada a isso e o ANP, por sua vez, demonstrou resultados coerentes ao inter-relacioná-los possibilitando, ao decisor, uma escolha coerente com o perfil estratégico da organização.

O PASS considera três fases:

\section{Fase I - Preparação}

Esta fase contém duas etapas: na primeira definem-se os critérios a serem avaliados. Esses critérios podem ser diferentes para cada empresa e devem ser definidos com a participação dos principais interessados na implantação. Na segunda etapa, para cada critério há a necessidade de se avaliar a sua aderência aos requisitos da organização. Isso pode ser feito pelo envio a cada um dos potenciais fornecedores a solicitação de RFI (Request for Information) que é uma requisição aos fornecedores para que informem qual ou quais de seus produtos podem atender uma necessidade específica ou, para informações mais completas, pela solicitação de RFP (Request for Proposal) que é um convite aos fornecedores para que eles submetam à organização as ofertas para produtos ou serviços específicos.

Outra possibilidade é a empresa ter em seu quadro de colaboradores profissionais os quais, graças à participação em avaliações anteriores, tenham conhecimento suficiente para atuarem nesta etapa como consultores internos. A aquisição de conhecimento externo é outra possibilidade, usual, pela contratação de consultores com experiência em diversas implantações anteriores.

\section{Fase II - Análise}

A análise dos critérios deve ser feito utilizando-se o ANP.

O ANP deve contê-las nos agrupamentos. Para uma análise menos aprofundada, no entanto, os agrupamentos devem analisar, no mínimo, os seus quatro domínios: estratégia e infraestrutura de Negócio e de TI, possibilitando assim a análise do impacto do julgamento quanto à importância do Negócio em face da TI e a análise da sensibilidade de forma mais precisa.

\section{Fase III - Avaliação e definição da aquisição}

Esta fase também passa por duas etapas: na primeira é feita a análise da sensibilidade da importância atribuída ao par Negócio/TI, verificando o quanto a classificação dos ERPs pode modificar-se conforme o grau dos experimentos, na segunda etapa, finalmente, define-se o ERP a ser adquirido e efetua-se a negociação final.

O diagrama apresentado na figura 4.1 representa o modelo de aplicação do PASS. 


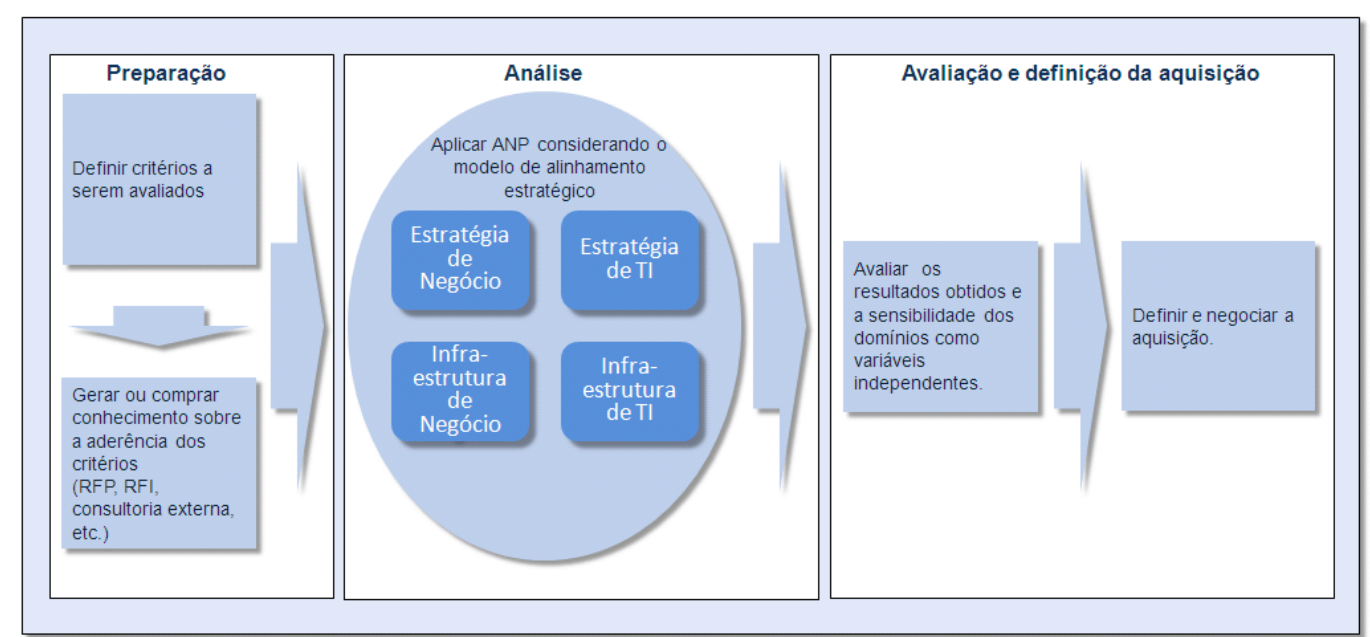

Figura 4.1

Procedimento de Avaliação para Seleção de Sistemas Integrados de Gestão (PASS).

\section{Referências bibliográficas}

BAKI, B.; ÇAKAR, K. Determining the ERP package-selecting criteria: the case of Turkish manufacturing companies. Business Process Management Journal. v. 11, n. 1, p. 75-86, 2005.

BINGI, P.; SHARMA, M.; GODLA, J. Critical issues affecting an ERP implementation. Information Systems Management, v. 16, n. 5, p. 7-14, Summer,1999.

BUONANNO, G.; FAVERIO, P.; PIGNI, F.; RAVARINI, A.; SCIUTO D. E TAGLIAVINI, M. Factors affecting ERP system adoption: A comparative analysis between SMEs and large companies. Journal of Enterprise Information Management. v. 18, n. 4, p. 384-426, 2005.

COLÂNGELO FILHO, L. Implantação de sistemas ERP.- Um enfoque de longo prazo. São Paulo: Atlas, 2001. 191 p.

CORRÊA, H.L. ERPs: Por que as implantações são tão caras e raramente dão certo? 199?a. Disponível em: <http://www.correa.com.br/biblioteca/artigos/

A10_ERPs_por_que_as_implantacoes_sao_tao_caras_e_raramente_dao_certo.pdf $>$. Acesso em: 20 maio 2003.

CORRÊA, H.L. Aspectos a considerar na seleção de uma solução ERP para médias empresas. 199?b. Disponível em:

<http://www.correa.com.br/biblioteca/artigos/A04_Computerworld_artigo_escolha_software.pdf >. Acesso em: 20 maio 2003.

; GIANESI, I.G.N. e CAON, M. Planejamento, programação e controle da produção. MRPII / ERP conceitos, uso e implantação. São Paulo: Atlas, 1997. 361 p.

EXTREME CHAOS. Extreme Chaos 2001. The Standish Group International, Inc, 2001. Disponível em: <http://www.standishgroup.com/chaos_resources/index.php>. Acesso em: 21 dez. 2003.

Extreme Chaos $2004-3^{\text {rd }}$ quarter research report. The Standish Group International, Inc, 2004. Disponível em:

<http://www.standishgroup.com/sample_research/PDFpages/q3-spotlight.pdf>. Acesso em: 27 ago. 2005. 
FITZGERALD, G. Evaluating information systems projects: a multidimensional approach. Journal of Information Technology, v. 13, p. 15-27, 1998.

HECHT, B. Choose the right ERP software. Datamation. v. 43, n. 3, p. 56-58, 1997

HENDERSON, J.C.; VENKATRAMAN, N. Strategic alignment: Leveraging information technology for transforming organizations. IBM Systems Journal. v. 32, n. 1, p. 4-16, 1993.

ILLA, X.B.; FRANCH, X.; PASTOR, J.A. Formalizing ERP selection criteria. In: $10^{\text {TH }}$ INTERNATIONAL WORKSHOP ON SOFTWARE SPECIFICATION AND DESIGN, IEEE, Anais... San Diego, 2000.

$\mathrm{KOCH}, \mathrm{C}$. The ABCs of ERP. CIO Magazine, December 22. 1999. Disponível em <http://www.cio.com/research/erp/edit/erpbasics.html>. Acesso em 14 out. 2005.

LAUDON, J.P.; LAUDON, K.C. Gerenciamento de sistemas de informação. 5 ed. São Paulo: Pearson, 2004. 562 p.

LAURINDO, F.J.B.; MESQUITA, M.A. Material Requirement Planning: 25 anos de história uma revisão do passado e prospecção do futuro. Gestão \& Produção, v. 7, n. 3, p. 320-337, dez. 2000

LUFTMAN, J.N.; LEWIS, P.R.; OLDACH, S.H. Transforming the enterprise: The business alignment of business and information technology strategies. IBM Systems Journal. v. 32, n. 1, p. 198-221, 1993.

MABERT, V.A.; SONI A.; VENKATARAMANAN, M.A. Enterprise Resource Planning: Common myths versus evolving reality. Business Horizons. V.44, n.6, p. 60-72, May-June, 2001

MARKUS, M.; TANIS, C. The enterprise systems experience- from adoption to success. In: Zmud R. W. (Ed.) Framing the domains of it research glimpsing the future through the past. Cincinnati: Pinnaflex Educational Resources, 2000. p. 137-207

NOLAN, R.; McFARLAN, F.W. Information technology and the board of directors. Harvard Business Review, v. 83, n. 10, p. 96-106, Oct. 2005.

O'BRIEN, J.A. Sistemas de informação e as decisões gerenciais na era da Internet. 2ed, São Paulo:Saraiva, 2004. 436 p.

RAO, S.S. Enterprise resource planning: business needs and Technologies. Industrial Management \& Data Systems, v. 100, n. 2, p. 81-88, 2000

SAATY, T.L. Decision making with dependence and feedback. The analytic network process. 2ed. Pittsburgh: RWS Publications, 2001. 376 p.

Theory and applications of the analytic network process. Decision making

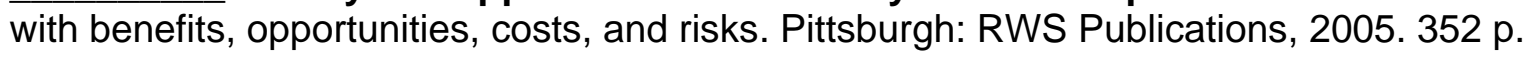

SLACK, N.; CHAMBERS S., JOHNSTON, R. Administração da produção. 2ed, São Paulo: Atlas, 2001. 747 p.

SOMERS, T.M.; NELSON, K. The impact of critical success factors across the stages of enterprise resource planning implementations. In: PROCEEDINGS OF THE $34^{\text {th }}$ HAWAII INTERNATIONAL CONFERENCE ON SYSTEMS SCIENCES, Jan.3-6 Anais... Maui, 2001, p. 1-10.

TELTUMBDE, A. A framework for evaluating ERP projects. International Journal of Production Research. v. 38, n. 17, p. 4507- 4520, 2000. 